\title{
Cases of Neuroblastoma Missed by the Mass Screening Programs
}

\author{
MOTOI NISHI, HIROTSUGU MIYAKE, TAKEO TAKEDA, NOBUO TAKASUGI, \\ YASUMASA SATO, JUNJI HANAl, AND TSUNEAKI KAWAI \\ Department of Public Health, Sapporo Medical College [M.N., H.M.]. the Department of Pediatrics, Sapporo \\ National Hospital [T.T.], and Sapporo City Insitute of Public Health [N.T., Y.S., J.H., T.K.], Sapporo, Japan
}

\begin{abstract}
Twenty-two reported cases of neuroblastoma missed by the mass screening programs were reviewed (six cases in Sapporo City where a quantitative measurement for both vanillylmandelic acid (VMA) and homovanillic acid (HVA) is used and 16 cases in the districts of qualitative judgment only for VMA), and some potential factors for missing a patient were discussed. Most of the 22 patients were diagnosed over $12 \mathrm{mo}$ and had advanced clinical stages at diagnosis (III or IV). Of the 17 cases whose outcome in prognosis was available, nine cases were dead and only three cases were alive without any trace of tumor. Fluctuation in the amounts of urinary VMA and HVA seemed to be one of the causes for missing a patient, especially with a small tumor. The comparison about tumor wt, VMA and HVA amounts, and clinical stage between the 22 true positive cases in Sapporo City and 46 ones in the districts of qualitative methods, and the difference in detection rate between the two groups suggested that the qualitative methods missed more patients with a small tumor. The patients who had abnormally high amounts of HVA with low amounts of VMA accounted for a fairly large part of the missed cases in Sapporo City as well as in the districts of qualitative methods. To the contrary, no patient of this type was found even among the 22 true positive cases in Sapporo City. (Pediatr Res 26: 603-607, 1989)
\end{abstract}

\section{Abbreviations}

VMA, vanillylmandelic acid

HVA, homovanillic acid

Mass screenings of neuroblastoma are now being performed in many self-government bodies of Japan for the purpose of early detection. Although satisfactory results are being obtained $(1,2)$, several missed cases have been reported sporadically from some districts. By March 1989 in Sapporo City, where the mass screening program started in April 1981, whereas 22 true positive cases were detected; however, six children developed this disease after they had been judged to be negative at the mass screening. (Consequently, its sensitivity is $78.6 \%$.) Although such cases may

Received April 12, 1989; accepted July 14, 1989

Correspondence Motoi Nishi, Department of Public Health, Sapporo Medical College, S.1, W.17, Sapporo, Hokkaido 060, Japan.

Supported in part by a grant-in-aid for cancer research from the Ministry of Health and Welfare of Japanese Government.

'Other members of the study group were: A. Tsunoda, M. Hirayama, Y. Akiyama, S. Sawaguchi, K Yamamoto, Y. Hanawa, R Koide, S. Suzuki, T Haibara, K. Nishihara, H. Komiya, C. Obara, T. Nükawa, K. Shimizu, R. Nakata, T. Sawada, N. Nagahara, and A. Kowatari. reduce the effectiveness of the mass screening, the study may give useful information about biologic matters of this disease as well as about the improvement of mass screening programs. Until now, there has been no literature comprising a comprehensive survey. In our report we summarize the missed cases reported and discuss some potential causes that give birth to them.

\section{REPORTED MISSED CASES}

Although almost all of the mass screenings of neuroblastoma in Japan are aimed at infants aged about $6 \mathrm{mo}$ and filter papers are used for urine sampling, the screening methods differ in certain details (3). Therefore, the strict definition of a missed case should be different according to the method used. But in our study, tentatively and inclusively, a missed case is defined as a patient who had been judged to be negative at a mass screening and proved thereafter to have this disease.

Table 1 shows the six missed cases in Sapporo City, one case in Hokkaido Prefecture (program started in 1985), and 15 cases who were reported in literature from other districts in Japan by March 1989 [Saitama Prefecture, four cases (started in 1981); Kanagawa Prefecture, five (1982); Nagoya City, two (1977); Aichi Prefecture excluding Nagoya City, one (1981); Kyoto Prefecture, one (1973); Osaka City, two (1980)] (4-8) (Tsunoda A, Kodama $K$, and Nagahara $N$, personal communication). Sapporo City adopts the quantitative measurement of both VMA and HVA by HPLC $(9,10)$. The other districts adopted qualitative judgment of only VMA (spot test or dip test) at the time of the screenings of these cases (4-8).

Inasmuch as no report is available about the sensitivities of other districts than Sapporo City, the cases in our report may not necessarily be all the missed cases identified.

Advanced clinical stages at diagnosis (III and IV) accounted for $90.9 \%$ (20 of the 22 patients). Most of them $(86.4 \%, 19$ of the 22 ) were diagnosed after $12 \mathrm{mo}$. Of the 17 patients whose outcome in prognosis was available, only three cases (patients 1 , 18 , and 21) were alive without any trace of tumor and considered to be cured. (The case of patient I was accidentally found through a chest x-ray examination for bronchitis.) Nine patients died of this malignancy (six of them within 1 y). The remaining five cases were alive with tumor at the time of their reports.

Pathologic information of primary tumor site was available for seven patients; the tumors of patients $1,5,6$, and 7 were ganglioneuroblastoma, and patients 3,4 , and 13 were neuroblastoma. Although the specimen of patient 1 was obtained before chemotherapy, those of patients 3-7 were after intensive chemotherapy. No information was available about the time when the specimen of patient 13 was obtained. The specimens of patient 2 were obtained only from bone marrow and pleural effusion, both of which revealed rosette formation of metastatic tumor cells. 
Table 1 . Missed cases in mass screenings of neuroblastoma*

\begin{tabular}{|c|c|c|c|c|c|c|c|c|}
\hline \multirow[b]{2}{*}{ Patient } & \multirow[b]{2}{*}{ Sex } & \multicolumn{2}{|c|}{$\begin{array}{c}\text { Age }(\mathrm{mo}) \\
\text { at }\end{array}$} & \multirow[b]{2}{*}{ Stage $^{12}$} & \multirow{2}{*}{$\begin{array}{c}\text { VMA HVA } \\
\begin{array}{l}\mu \mathrm{g} / \mathrm{mg} \mathrm{Cr} \\
\text { (mg/day) }\end{array}\end{array}$} & \multirow[b]{2}{*}{ HVA/VMA } & \multirow[b]{2}{*}{$\begin{array}{l}\text { Tumor } \\
\text { site }\end{array}$} & \multirow[b]{2}{*}{$\begin{array}{c}\text { Alive or } \\
\text { dead } \dagger\end{array}$} \\
\hline & & Scr & Diag & & & & & \\
\hline 1 & $\mathrm{M}$ & 8 & 19 & III & $(26.324 .0)$ & 0.91 & med & $A(69)$ \\
\hline 2 & $\mathrm{M}$ & 7 & 19 & IV & $2 \xi .8 \mathrm{~J} 25.5$ & 5.76 & L-adr & D $(5)$ \\
\hline 3 & $\mathrm{M}$ & 7 & 16 & IV & 21.9123 .6 & 5.64 & $\mathrm{R}-\mathrm{ad} r$ & $D \times 6)$ \\
\hline 4 & $\mathrm{M}$ & 8 & 29 & IV & 37.0334 .5 & 9.04 & L-adr & $D(7)$ \\
\hline 5 & $\mathrm{M}$ & 6 & 59 & III & 143.164 .5 & 0.45 & R-adr & $A(18)$ \\
\hline 6 & $F$ & 7 & 29 & IV & 91.470 .1 & 0.77 & R-adr & $D(15)$ \\
\hline 7 & $\mathrm{M}$ & 7 & $2 i$ & IV & 20.5322 .9 & 15.75 & R-adr & $D(19)$ \\
\hline $8^{4}$ & $\mathrm{M}$ & & $16 \ddagger$ & III & $(5.827 .5)$ & 4.74 & R-adr & $D(7)$ \\
\hline $9^{4}$ & $\mathrm{~F}$ & & $27 \ddagger$ & IV & $(8.121 .3)$ & 2.63 & $\mathrm{adr}$ & $A(2)$ \\
\hline $10^{5}$ & & & 8 & IV & $(7.6)$ & & & \\
\hline $11^{5}$ & & & 11 & III & 160 & & & \\
\hline $12^{4}$ & $F$ & & $10 \ddagger$ & II & $(7.05 .6)$ & 0.80 & med & $A(3)$ \\
\hline $13^{6}$ & $M$ & $7^{13}$ & 18 & II & $71.1^{13} 35.6^{13}$ & 0.50 & neck & $A(17)^{13}$ \\
\hline $14^{6}$ & $M$ & & 27 & IV & & & $\mathrm{adr}$ & \\
\hline $15^{6}$ & $\mathbf{M}$ & & 21 & IV & & & $\mathrm{adr}$ & \\
\hline $16^{6}$ & $\mathbf{M}$ & & 18 & IV & & & $\mathrm{adr}$ & \\
\hline $17^{7}$ & $\mathrm{~F}$ & $4^{14}$ & 37 & IV & 57.91554 .1 & 26.67 & L-adr & $D(9)$ \\
\hline $18^{7}$ & $\mathrm{~F}$ & $6^{14}$ & 14 & III & 258146 & 0.57 & rtp & $\mathrm{A}(89)^{14}$ \\
\hline $19^{4}$ & $\mathrm{M}$ & & $14 \frac{1}{t}$ & IV & $(6.518 .6)$ & 2.86 & L-adr & $A(5)$ \\
\hline $20^{4}$ & $F$ & & $29+$ & IV & $(68.929 .0)$ & 0.42 & $\mathrm{rtp}$ & $D(6)$ \\
\hline $21^{8}$ & $\mathbf{M}$ & $8^{15}$ & 28 & III & $(1.3820 .7)$ & 15.0 & L-adr & $A(34)^{15}$ \\
\hline $22^{8}$ & $\mathrm{~F}$ & $6^{15}$ & 15 & IV & & & L-adr & $D(32)^{15}$ \\
\hline
\end{tabular}

* Patients 1-6, Sapporo; 7, Hokkaido; 8-11, Saitama; 12-16, Kanagawa; 17-18, Nagoya; 19, Aichi; 20, Kyoto; 21-22, Osaka. scr, screening; diag, diagnosis; L, left; R, right; med, mediastinum; adr, adrenal gland; rtp, retroperitoneum; A, alive; D, dead.

† Months from diagnosis.

$\ddagger$ Age at operation.

\section{DISCUSSION}

The prognosis of a missed patient is poor as described. Therefore, prevention may be one of the most important things for the mass screening.

It is probable that a patient with a small tumor is missed on the grounds that his amounts of VMA and HVA fail to reach "cut-off" levels. Figure 1 shows the fluctuation of the amounts of VMA $(\mu \mathrm{g} / \mathrm{mg} \mathrm{Cr})$ of the two true positive cases with small tumors ( $11 \mathrm{~g}$ and $10 \mathrm{~g}$ ) in Sapporo City. During hospitalization, urine samples were taken randomly during consecutive $24-72 \mathrm{~h}$ by filter papers and were kept at $4^{\circ} \mathrm{C}$ until measurement. Urine samples were also taken randomly by syringes from the urine packs attached to the infants during another consecutive 24-72 $\mathrm{h}$ and were kept at $-20^{\circ} \mathrm{C}$ until measurement. Within $2 \mathrm{~d}$ from sampling, the amounts of VMA and HVA were measured by HPLC in Sapporo City Institute of Public Health. The amounts of VMA fluctuated regardless of sampling method, and the greater part of these values were less than $20-25 \mu \mathrm{g} / \mathrm{mg}$ Cr which is the range of the cut off values usually used in HPLC methods. (Incidentally, the minimum VMA value in 28 "filter paper" urine samples of a true positive case of Sapporo City with a tumor of $24.5 \mathrm{~g}$ was $20.5 \mu \mathrm{g} / \mathrm{mg} \mathrm{Cr}$, and in nine of 28 samples, VMA amounts were under $25 \mu \mathrm{g} / \mathrm{mg} \mathrm{Cr}$. But the minimum VMA amount in 21 "filter paper" urine samples of another true positive case with a tumor of $60.7 \mathrm{~g}$ was $48.4 \mu \mathrm{g} / \mathrm{mg} \mathrm{Cr}$.) The amounts of HVA also fluctuated, ranging from 22.1 to $62.5 \mu \mathrm{g} /$ $\mathrm{mg} \mathrm{Cr}$ in filter paper urine of the case with a tumor of $11 \mathrm{~g}$, and from 22.1 to $31.5 \mu \mathrm{g} / \mathrm{mg} \mathrm{Cr}$ in the case of $10 \mathrm{~g}$. (The range of cut off values of HVA usually used is $30-40 \mu \mathrm{g} / \mathrm{mg}$ Cr. The intra- and interassay variations in the Institute is less than $4 \%$ for each substance.)

Consequently, these two patients were lucky to have been detected, because the detection of a tumor may be a matter of probability. Those who have higher average amounts of urinary VMA or HVA may have higher probability to be detected. But



Fig. 1. Fluctuation of the amounts of urinary VMA $(\mu \mathrm{g} / \mathrm{mg}$ of creatinine) at diagnosis in the two true positive cases in Sapporo City.

even a patient with a large tumor can be overlooked if the amounts of both VMA and HVA chance to be lower than the cutoff values when screened. That is, only one normal result cannot always guarantee that the infant is free from neuroblastoma. Thus, the fluctuation seems possible as one of the 